\title{
Unintended consequences of translation technologies: From project managers' perspectives
}

\author{
Akiko Sakamoto \\ School of Languages and Area Studies, University of Portsmouth, Portsmouth, UK \\ Park Building \\ King Henry I Street \\ Portsmouth PO1 2DZ \\ UK
}

Acknowledgments

I would like to extend my gratitude to the study participants for taking time out of their busy schedules to share their insights. This study was conducted as part of the larger project, When Translation Meets Technologies: Language Service Providers (LSPS) in the Digital Age, funded by the University of Portsmouth.

Bio note

Akiko Sakamoto is senior lecturer in translation studies and Japanese language at the University of Portsmouth, UK. She holds a PhD in translation studies from the University of Leicester, UK. Her research interests include sociology of translation, particularly the influence of technology on translation practitioners and users, pedagogy of translation and translation theories. She previously worked as an English - Japanese translator. 


\title{
Unintended consequences of translation technologies: From project managers' perspectives
}

\author{
Recent years have seen the advance of increasingly efficient translation and \\ translation-related technologies such as neural machine translation and \\ crowdsourcing-style translator procurement platforms. These AI, big-data and \\ algorithm-driven online systems are hailed as successes in the media- and \\ technology-vendor-led public discourse. However, in light of the notion of \\ 'solutionism' (Morozov, 2013), there may be a risk that unintended adverse \\ consequences of these technologies on users remain obscured. As a result, a \\ correct assessment of the influence of technologies on human actors may become \\ difficult. In order to identify such unintended consequences of translation \\ technologies, the present article explores technology users' perceptions about \\ how the technology is affecting their business practice. The discussion draws on \\ data collected in a focus group study with 16 translation project managers. The \\ study reveals that project managers are feeling a high level of uncertainty and \\ unease about the effects of technology when they talk about business practices, \\ particularly in the following areas: translators' use of MT, pricing for post- \\ editing, post-editors' profiles and skills and technology-induced new power \\ struggles in the industry.
}

Keywords: translation technology, focus group, language service providers, project managers, machine translation, paid-crowdsourcing

\section{Introduction}

Technology has become established as a prominent feature of the translation industry. The Association of Translation Companies' UK industry report (Dranch, 2016, pp. 2324) indicates that UK language service providers (LSPs) are increasingly seeking higher profits by optimising translation memory use and incorporating post-editing machine translation (PEMT) in their operations. Recent media and industry discourse is rife with reports about the latest translation technologies, which use cutting-edge innovations such as big data, AI (artificial intelligence) and algorithms. The most prominent of those 
is neural machine translation. Google Translate can now translate in "103 languages that cover $99 \%$ of the online population" and the quality of translation is expected to improve further as the systems are trained with more data (Google, 2014). New products such as an instant-translation earpiece, which resembles the Babel Fish in the 1980s' comedy science fiction The Hitchhiker's Guide to the Galaxy (Adams, 1979/2016), will offer "a fluid and continuous multilingual conversation similar to a real-life experience" (Waverly Labs, 2017). If you need a human translator, paidcrowdsourcing translation service platforms will find one for you in a way that is similar to finding an available taxi on a ride-hailing smartphone app.

Consequently, people's perception of translation is changing: translation is expected to be immediate, straightforward and easy in the form of what Bruno Latour (2003) calls “double-click communication", which is "every mouse owner's dream" (p. 146). This expectation, in turn, erodes translators' "chrono-diversity", namely, "the need to protect different rhythms, different experiences of time, in order to safeguard and maintain human well-being" (Cronin, 2013, p. 94), and as a consequence, translators' working conditions and professional status are suffering. As Cronin writes: "The sense of recurrent temporal deficit, of never doing enough fast enough, is a powerful agent of despair, and an important source of stress for translators" (2013, p. 94).

Another source of stress for translators is the fear that computers will take over from human translators and this is exacerbated as translation is now commonly recognised as a product of human-machine interaction (O'Brien, 2012). In a time when many jobs are thought to be susceptible to computerisation (Frey \& Osborne, 2013), this fear is understandable and unavoidable. 
In this environment it may be easy to become resigned to the idea that technology is unstoppable and that we must accept its consequences. Technology critic Evgeny Morozov calls this stance "digital defeatism", which, "-- by arguing that this amorphous and autonomous creature called 'Technology' with a capital $T$ has its own agenda -- tends to acknowledge implicitly or explicitly that there's little we humans can do about it" (2013, p. 213). By “Technology”, Morozov means internet-based Silicon Valley service providers like Google and Facebook, whom he scornfully criticises for spreading the ideology of "solutionism". He defines solutionism as a never-ending quest to solve a problem which does not exist in the first place.

Solutionists, with their overenthusiasm about the value and capability of modern digital technologies, strive to recast complex social problems either as neatly defined problems, which, they claim, can be solved by computable solutions, or as transparent processes that can be optimised with the right algorithms. But complexity is not in itself problematic: social conditions in general are complex in nature. Morozov criticises solutionists' short-sighted eagerness to solve problems using technologies while being only perfunctorily interested in the activity for which improvement is needed. In other words, solutionists' interest focuses on the use of technologies for their own sake rather than in engaging earnestly with the ostensive problems. Morozov warns that, as a result, solutionists may cause "unexpected consequences that could eventually cause more damage than the problems they seek to address" (p. 5). For Morozov, the problem is the recent public discourse, or "tool talk" (p. 167), in which "innovation is seen as having only positive effects", and therefore, "few are prepared to examine its unintended consequences; as such, more innovations are presumed to be self-evidently good" (p. 167). 
Recent literature increasingly deals with those unintended consequences of technological innovation in translation. Some research deals with specific technologies and their effects on translators, such as translation memory (Garcia, 2007; LeBlanc, 2017; Moorkens, Lewis, Reijers, Vanmassenhove, \& Way, 2016), machine translation (Kenny \& Doherty, 2014), and translation crowdsourcing (Flanagan, 2016; Garcia, 2015; O'Hagan, 2017). Other works deal with social and economic effects in translation (Moorkens, 2017), provide a conceptual and methodological framework (Olohan, 2011) or offer theoretical frameworks for the overall situation (Cronin, 2013). Kenny calls this line of research "STS (science and technology studies) inspired approaches to translation technology" ${ }^{1}$, but says such work is still "few and far between" $(2017$, p. 6).

This article examines where these unintended consequences are felt by translation project managers (PMs) using the data obtained in a focus group study. PMs were chosen as study participants because they are important yet understudied stakeholders in the translation production network ${ }^{2}$, who are not only "the hub of the translator's work environment", but also play "a critical role in the organization in order to mediate between all the stakeholders (Rodríguez-Castro, 2013, p.40). As such, PMs' actions influence translators' attitudes and behaviours, and eventually the quality of translation (Sakamoto, 2017). While it is admittedly difficult to define a project manager's job, which varies depending on the LSPs' sizes, priorities in business and organisational structures, the shared feature of their job, i.e., the mediating role between

\footnotetext{
${ }^{1}$ STS is an interdisciplinary field of study conducted by sociologists, philosophers, historians and anthropologists. It examines the interactions between and mutual influence of technology and human agency and behaviours. For the history and terrain of STS, see, for example, Sismondo (2010) .

${ }^{2}$ For recent work examining PMs, see Olohan and Davitti (2015)
} 
translators and clients or translators and management, will mean that PMs' perceptions and opinions will reflect the tensions between those different groups of stakeholders, which will be a suitable site for observing unintended consequences.

\section{The study}

\subsection{Methods}

The focus group study was conducted using 16 project managers (PMs) from 15 UK LSPs. The focus group method has some advantages over quantitative methods such as questionnaire surveys. While questionnaire surveys provide useful snapshots of the status of the industry numerically such as the uptake of machine translation (e.g. ELIA et al., 2017; The European Commission, The CIOL, \& The ITI, 2017; Zaretskaya, Corpas Pastor, \& Seghiri, 2015), the focus group is suitable for "elicit(ing) people's own understandings, opinions or views" (Wilkinson, 2008, p. 347).

Focus groups also allow for the observation of delicate interactions between participants. Participants have their social stakes in the focus group where they are placed with other participants who have the same job profile as them. Therefore, "we cannot assume that by asking questions we can elicit directly their cognitions as essentialist research may expect” (Wilkinson, 2008, p. 347). Each participant may feel that "he/she is a competitor of the other participants or feel rather comradely towards others" (p. 347). In the present study, participants from similar working conditions (in terms of size of the LSP) were grouped together so that the homogeneity would facilitate lively discussions as they had similar experiences in their work settings (Morgan, 1997, p. 36), and I feel this was the case: the participants quickly established a rapport among themselves during the discussions. 


\subsection{Procedure}

Four focus group meetings (with four participants in each group) were conducted on 9 June 2016 in parallel, with one researcher moderating one group each (thus four researchers worked simultaneously).

Ten questions covering the following areas as well as two rounding-up questions were asked: 1) machine translation; 2) CAT tools; 3) interpreting-related tools; 4) training of digital tools; 5) paid-crowdsourcing business model; and 6) communication tools (see Appendix for the questions). The questions were designed after analysis of technology-related topics found in recent academic literature and industry discussion. The latter included translators' blogs, forum posts on Proz.com (https://www.proz.com) and articles on Slator (https://slator.com) and the Common Sense Advisory's website (https://www.commonsenseadvisory.com). The questions were intentionally broad to give discussions scope for spontaneous development according to the participants' interest, whether positive or negative. The moderators rehearsed mock discussions with pre-determined scripts and discussed anticipated problems to ensure uniformity of moderation between the groups. The discussions lasted for 2 hours with a 10-minute break in the middle. The discussions were audio-recorded and transcribed for analysis.

\subsection{Participants}

Participants were recruited who met the following two criteria: 1) The person works for a UK Language Service Provider (LSP) or is a business owner of a language service company; 2) The person assumes a project management responsibility in the workplace or oversees project management operations. The participants responded to one of the three calls for participation: 1) All corporate members of ITI (Institute of Translation and Interpreting) and ATC (Association of Translation Companies) were approached by 
email; 2) Out of those companies, those that are located in London or South of England (which is geographically close to the location of the focus groups) were approached by telephone; 3) An open call for participation was given on the project's webpage.

Sixteen people volunteered to take part, who were grouped into four according to the size of the company (in terms of the number of employees): Group 1 (participants from companies which have 1-2 employees); Group 2 (3-12 employees); Group 3 (1525 employees) and Group 4 (19-150 employees). There was an overlap of numbers between Groups 3 and 4 because one company (of the business size of 25 employees) sent two participants to the meetings. Group 1 included two participants who were sole traders (thus their employee number is one).

At the time of registration the participants filled in an online questionnaire about their career profiles and the companies' technology use. On average the participants had 12.25 years of experience in the translation industry (ranging from 3 to 28). Out of the 15 LSPs, 13 used translation memory systems (either stand-alone or server-based or both). Five LSPs used a localization tool and four owned an in-house proprietary machine translation system. With regard to project management system, two used a generic product (such as MS Project), five used a translation specific system (such as LTC Worx or Projetex), seven used a bespoke system, out of which three used two systems in parallel. Five LSPs owned online client/vendor portals and two owned a client portal only. Twelve companies used social media for corporate communication. These outcomes show that participants' companies had a wide range of profiles with regard to technology use. In this report, the identifiers indicate participants by their group number and an individually-assigned number (for example, G1-1 means Participant 1 in Group 1). 


\subsection{Analysis}

Transcriptions of the discussions were coded using qualitative analysis software NVivo. Coders also listened to the audio-recording files during the analysis so as not to miss any nuances of the discussions such as silences and laughter. Concepts were generated from transcripts of answers to each question across the groups using a grounded theory approach (Glaser \& Strauss, 1967), in other words, identifying commonly occurring concepts and categories in the discussions in an inductive manner. To do this, two steps of coding were taken following Richards and Morse (2007, pp. 177-183): first, by 'open-coding' whereby segments of a transcript were coded with freely generated labels, and then by carrying a 'category search' where common categories across the labels were identified to generate more abstract notions or themes. Each question was coded by two researchers separately, then the results were compared to ensure inter-coder reliability. When there was a discrepancy in the interpretation of data between the researchers, they compared their coding data and discussed the results until they agreed on common concepts and themes. Because of the fairly small number of participants the analysis does not intend to observe the differences between the groups but rather the overall trends across the groups. The number of accounts was counted by the frequency of the topic being discussed. One count can consist of part of an utterance by one speaker or a stretch of conversation between several participants.

\section{Results and discussion}

The detailed outcomes of the focus groups are reported in Sakamoto, Rodríguez de Céspedes, Berthaud, and Evans (2017) so this article does not repeat them. The overall picture demonstrates that the PMs are active users of technology, who are constantly on the lookout for new technologies to improve their operations and meet client demands. They try hard to learn about new online services and products, particularly when there is 
a need from their clients ("People [PMs] often have got no background or training in it and clients are wanting to buy it so we have to go and find a way to get training and experience in it to be able to deliver it." (G4-3)). One such example is API (Application Programming Interface) although they admitted time constraints are always a hindrance, particularly in smaller companies. They are keen to learn from industry publications (such as Common Sense Advisory reports) and from competitors ("I've often said to my project managers (jokingly), 'Could you go and work for another agency and then come back', so I can see how somebody else does it, if there's an easier way!"' (G1-4)).

Although the participants showed positive attitudes towards many aspects of technologies such as their time and cost saving effects and convenience ("How did people live without Google, honestly?" (G1-2); "Email probably would be the most important thing [for marketing]." (G4-4)), the analysis has identified some areas in which they are experiencing negative effects of the technologies, which are the focus of this article. Two of the most prominent areas will be discussed below.

\subsection{Uncertainty surrounding the use of machine translation (MT)}

\section{Use of MT by translators ${ }^{3}$}

In current translation practice, MT can be used in two different environments. One is personal use by translators as part of their own translation process: for post-editing MT outputs (sometimes using MT-plugins in a CAT tool); for understanding the gist of a

\footnotetext{
${ }^{3}$ The outcomes of this section are based on the following categories generated in the analysis:

"PMs' positive attitudes with proviso" (35 counts across the 4 groups); "Whether translators use MT or not" (11 counts/3 groups); "Company policy about translators' MT use" (8 counts/3 groups); and "Uncertainty about MT use" (8 counts/3 groups), all for Q1 .
} 
source text, or simply for using it as a dictionary. The other is to use MT in a more formal, systematic process organised by the LSP as part of post-editing machine translation (PEMT) service, where a translator works as a post-editor.

This section first deals with the former method. Literature reports different figures of uptake of MT by freelance translators, which range from 22\% (The European Commission et al., 2017), 33\%, (ELIA et al., 2017) to 36\% (Zaretskaya et al., 2015). One of the questions in the focus groups, "How much do you think translators should use MT in their practice?", revealed that PMs are cautiously positive about their translators using MT at the personal level:

"If it's relevant to the project, it can be quite a help." (G3-2)

"[They should use it] [a]s much as it helps, as long as they use it appropriately." $(\mathrm{G} 2-3)$;

"I find it quite beneficial sometimes, for certain texts" (G2-1).

However, their knowledge is extremely limited when it comes to the question of how much their translators are actually using MT. One of the reasons is because "if they [translators] really don't like it [MT], then they tend to be very vocal" (G2-4). In other words, if translators use MT and are happy about it, they tend not to talk about it with PMs. PMs feel translators are afraid of talking about MT openly, and when PMs approach them to discuss it, "It's like, the knives come out [laughter]" (G2-1). Therefore, PMs do not have much opportunities to talk about it with their translators, but they assume "they [translators] are using it without saying" (G2-4).

At the corporate level, LSPs are not proactively taking action about this issue. Some participants said their companies do not provide any guidelines about MT use to their translators and no PMs said their companies explicitly encourage their translators to use MT. Some said their companies ban translators from using MT to avoid possible 
copyright infringement against their end clients. For example, "we have Confidentiality Agreements in place and, therefore, public MT is just a non-starter" (G4-3). But at the same time, they are not implementing any measures to check the translators' compliance with the ban. As a result, PMs suspect their translators may be using MT despite the ban, and they admit that, as a consequence, LSPs themselves "are using machine translation by default" (G2-4).

The anxiety about legal consequences seems to be the main hindrance to open discussion. PMs are worried about the legal implications of letting translators use MT, but they also feel they cannot stop them from using it in this highly technologised environment. As a result, the topic of MT has become a “'don't ask, don't tell' kind of thing" (G2-2), making it a "grey area" (G3-1). One participant even said rather sarcastically, "If one of my translators wanted to use machine translation, I wouldn't want to know; as long as the work came back with the right quality, I don't care how they get there" (G1-4). This statement was followed by the sympathetic laughter of fellow participants.

In an age of the transition from human translation to human-machine translation, this 'don't ask don't tell' culture (described with the phrase which originally comes from the US policy on military service by LGBT soldiers, which was in force from 1993 to 2011) can be understood as a worrying trend. This reluctance towards open dialogue with translators about MT use can mean a lack of control by LSPs over translators' work process, which suggests ineffective project management. This culture may partly be a product of PMs' self-defence mechanisms (so that they do not get caught out with legal issues), but it is also preventing the industry from building a much-needed consensus on MT-use best practice. 


\section{Pricing for post-editing ${ }^{4}$}

With regards to the second method of MT use, i.e., using MT as part of PEMT, Dranch (2016, p. 24) reports $41 \%$ of LSPs now offer a PEMT service in the UK and this figure is expected to rise. In contrast, according to the questionnaires filled out by our participants, only two participants said their companies offered PEMT as part of their services at the time of the focus groups, eight participants said their companies did not offer the service and six companies did not answer the question. Out of all the participants, only one expressly stated in the discussion that PEMT is the way forward in the industry and "[i]f the translator says no to that, then they are cutting themselves out of future work streams" (G4-3). It is not clear why six companies did not answer the question, but the reason may be that their companies offered the service only on an adhoc basis when their clients requested, thus did not have a definite yes or no answer.

Some of our participants did report that they had been receiving an increasing number of enquiries from their existing and potential clients about PEMT. And overall, our participants expressed negative feelings about such enquiries due to the economic intentions of the clients. More and more of their clients now "know that [PEMT] is the way of getting savings" (G3-2). They have started to send MT output generated by a free, open-access MT system (such as Google Translate) and ask the LSP to edit it "because they want to pay you much less for it" (G3-2), to which our participants showed a negative reaction saying, "[I]t's nonsense" (G3-1) and "we refuse that. We will proof-read something that's written by a person" (G3-2).

\footnotetext{
${ }^{4}$ The outcomes of this section are based on the category "Cost and pricing" for Q1 (21 counts/4 groups).
} 
What is bothering the PMs is the fact that their clients perceive PEMT as a way of cutting costs, which has the potential to squeeze the LSP's profit margins, and consequently the translators'. But at the same time, they admit that they will need to accept a PEMT service if "costing really is an issue" (G1-3), implying that PEMT may become the last resort to satisfy their clients' drive for cost cutting.

PMs reported that their translators are reacting negatively to PEMT too, because "they're automatically looking at it as somebody's trying to take away from the cost side of things" (G2-4). PMs are also aware that pricing is not simple with PEMT. One participant expressed her feeling of confusion:

Even if the translator changes [an MT output] completely, that doesn't mean the machine translation wasn't useful. But equally, even if they don't seem to have changed it that much, that doesn't mean it was actually that good. It's very hard to say exactly what it is that you charge for. (G2-3)

Literature on pricing of the PEMT service is thin in translation studies with the exception of Vashee (2013), who maintains that, contrary to our PMs' belief, PEMT should not necessarily bring lower pay to post-editors compared to traditional human translation. Vashee states:

... given the current negative impression of PEMT held by many (if not most) translators, it is advisable to err on the side of caution and adopt a generous scale for post-editing that pays more per hour than straight translation work. (p. 144)

Vashee's opinion is in stark contrast to the belief which dominated our focus group discussions, that is, that PEMT has to be cheaper than human translations.

One point which was missing in the focus group discussions was the view that pricing is not just about unit price. The current standard practice in the industry is to pay the same rate for all MT post-editing work, and this rate is set at a fraction of the full 
per-word translation rate, which was at around 61\% in 2013 (Vashee 2013, pp. 142143). This is very likely the source of resentment expressed amongst translators and PMs in the focus groups. However, what is important for translators is, in reality, how much pay a translator takes home for the whole project. If the MT outputs are of a high quality and the post-editing process is fast, a larger number of words get processed and the final income will be higher. This logic was, however, absent in the focus group discussions. An appropriate pricing structure in the industry is an area which needs much more attention, and for that, more unbiased and evidence-based information is needed.

\section{Post-editors' profiles and skills ${ }^{5}$}

PMs' concern about PEMT is related not only to economic factors but also the conceptual framework of a 'translator'. PMs seem to have a firm idea about the ideal profile of a translator. One participant used the term "normal translator", describing the profile of such a translator as "someone who has a linguistic and domain capability, may or may not use translation tools, has some experience (at least five years) and is paid to translate a document from beginning to the end to a high level" (G4-1). This profile of the ideal traditional translator was agreed by the other participants and there was even the air of romanticising the concept when this was discussed. In this light PMs' concern is that their skilled 'normal' translators may be discouraged to stay in the industry if PEMT becomes the mainstream task for them because PMs believe postediting is boring and dull compared to human translation. This view echoes how the job of post-editing has been perceived in literature (Dranch, 2016; Moorkens \& O’Brien,

\footnotetext{
${ }^{5}$ The outcomes of this section are based on the category "Normal translator vs post-editor" for Q1 (18 counts/4 groups).
} 
2017) ${ }^{6}$.

On this issue, a sense of unease was evident in their outlook. Both translators and PMs are trying to understand the new question of who a translator and a post-editor is. One participant said aptly:

I think translators are struggling right now to understand what their role is. And for the next five/ten years, are we, as LSPs, looking at finding new translators, what the traditional translators are, or are we looking at finding revisers and editors and post-editors? What are we going to be doing? That is a big question mark, and it's probably what most of us don't want to face up to, if I'm being honest. (G4-1)

Pym (2013, p. 492) states this challenge is "primarily one of nomenclature", which has been caused because we try to "retain our traditional name but move with the technology". In other words, the concept of a 'translator' held by the PMs is not keeping pace with what the 'translators' are expected to do or are actually doing in another corner of the industry, creating pronounced uncertainties as to who they are working with now and who with in the future (translators or post-editors, or otherwise?). Again, this can lead to a loss of control of the translation production process for PMs.

\subsection{Technology-induced new power struggles ${ }^{7}$}

Another point the participants expressed to be troublesome in relation to technology is

\footnotetext{
${ }^{6}$ It is also important to add that two participants provided positive comments about post-editing.

One said seeing a MT output before translating is like having "that extra bit of energy" and he "find[s] that's fun" (G2-1). The idea that post-editing is boring may be a simplistic generalisation, which may deserve further testing.
}

${ }^{7}$ The outcomes of this section are based on the categories "Technology companies" (for Q1),

"Technology companies vs small companies" (Q5) and "Big and small companies" (Q6) 
the emerging power struggle between two polarizing ideologies in the industry, which I term here a 'them and us' discourse. Our participants seem to perceive that they belong to one group of actors in the industry ('us') while there is another group who they have a conflict with ('them') due to their use of technology. This discourse was apparent from the way PMs described the companies belonging to the "them" camp, using expressions such as "the really big multinationals", "tech-savvy people", "technology companies", "companies who have the software", "companies that are working with apps and start-ups" and "not linguistically skilled people".

The 'them and us' discourse was evident across the discussions of different questions. For example, in talking about communication tools, 'them' are the LSPs who use an automated communication system such as mass emailing to enquire about translators' availability. One participant thought "massive corporations have to do it that way", but smaller LSPs like her company do not because, by doing that "you're losing the personal relationship with them [the translators]. You don't want somebody to just feel like a number” (G2-4). In talking about MT, 'they' are the LSPs or clients who are eager to use MT to bring down translation costs (and note it is not only their competitors but also some clients who belong to the 'them' camp). The following remark clearly sums up PMs' feelings about it.

In my experience, it is the tech-savvy people. Maybe they even look at translation as a little bit old-fashioned. They think, "Well, I'm automating all of this stuff". And maybe companies that are working with apps and start-ups think, "Well, this is how things are done now, I can just put it into Google Translate on my phone". So maybe they think as it's progress, it must be better, even if they don't actually, necessarily, know whether or not it is. And a lot of the time it's things like

(total 10 counts/4 groups) as well as the categories "Negative", "Positive", "Control", "Price", "World trend" and "Image of translation" for Q6 (98 counts/4 groups). 
marketing content, and we have to ward them away from that and say, 'Please, no, no' (G3-4).

This remark clearly echoes Morozov's criticism of solutionism. The PM is frustrated that some technology-oriented LSPs see the intricate process of translation as a 'problem' which can be solved by technology, and, in their eagerness, try to 'solve' it which, for the PM, is an intrinsic complexity of translation, thus not necessarily a 'problem'.

The sense of resistance was also prominent when the participants were asked about the paid-crowdsourcing business model (Question 5). A paid-crowdsourcing business model is an online translator procurement system, where the matching of translators and clients - the traditional PMs' task - is replaced by algorithms on an online platform. Supported by venture capital or a larger parent company, new companies started this service from around 2008 (for details of this business model, see Garcia 2015). The focus group question asked if the participants' companies used this model and what benefits or disadvantages they thought this model would bring to the industry.

None of the participants said their companies used this model. One participant said their company tried to set up a similar, automated email enquiry system but gave it up as it took a lot of time and resources compared to an immediate gain. Another participant said his company was recently approached by an IT company to introduce this model, but the company decided not to. Apart from these participants, knowledge about this business model was limited amongst the PMs. After moderators explained this $\operatorname{model}^{8}$, participants showed surprise and then aversion and disapproval because,

8 For the purpose of the discussions, the moderators defined the term as a "[h]uman translation service with near-simultaneous turnaround", using a quote of the founder of Stepes 
they said, it would make it difficult to control translation projects ("... suddenly having a bunch of people that you don't know and you have, as far as I can see, very limited control" (G4-1)). ${ }^{9}$ They particularly disagreed with the model because vetting of translators would be difficult considering the size of the translator pool ("Do they vet them in terms of their qualification, or do they do tests or something?" (G2-2)); because the client-translator matching process lacks human input ("When we get a job in, we choose who's going to translate it quite carefully." (G2-3), "[With the system] you're going to get the wrong person [translator] doing it." (G2-2)); because the quality of translation is presumably low ("I can't ever think that the output is going to be anything other than pretty damn terrible." (G3-1)); and because of the lack of a human touch in project management ("we offer a tailored, one-to-one service, so crowdsourcing would be completely opposite" (G3-3)). Participants thought "people do business with people" (G4-3) and "most people, translators as well as clients, do want to talk to a person, even if they are emailing that person" (G4-2). There is a strong belief amongst the participants that project management is "a step of two-way process" (G4-4) and they thought the paid-crowdsourcing model denies this very core feature of project management.

Although a small number of positive comments were heard such as that "from a translator's point of view, if it's a new inexperienced translator, they could gain experience" (G1-4) and that "from a client's point of view it's a wonderful way of turning things round quickly in a lot of languages" (G1-4). However, positive comments

(Stepes, 2016) and gave an example of Gengo, which claims to have on their platform "over 15,000 native speakers - located in 140+ countries - translated more than 130 million words across 35+ languages" (“Gengo," n.d.).

${ }^{9}$ The views reported here are those of the participants and not intended to inform readers of any merits or disadvantages of the business model itself. 
were mostly sarcastic ("But from a project management point of view it's great, isn't it? Just send it out there, and then someone does it and sends it back [laughter]" (G2-1).)

A feeling of resignation, or a sense of digital defeatism in Morozov's term, was also felt; PMs admitted that the demands for cheaper and immediate service is "how our society is at the moment" (G1-4). But overall, a strong sense of resistance was evident ("Something has to change. It's wrong." (G1-2)) and they were worried that this kind of business might damage the image of translation overall ("I don't think it's an advantage to the industry, because it devalues what we do, and it's the reason why LSPs have quite a bad reputation" (G3-2)).

These reactions of the PMs suggest that they are proud of their role as human gatekeepers of translation whose task is to maintain the high quality of their products. This shared sentiment expressed in the focus groups echoes freelance professional translators' attitudes reported in Flanagan (2016, p.163) that translators are clearly irritated by the publicity this business model receives, "often being lauded as the new face of translation in the media, with most of the focus being on the technology rather than the human translators". The similarity between the sentiments of the two groups of stakeholders may come from the fact that most of our participants worked for relatively small LSPs, in which human connections between LSPs and translators are valued. Also the primary purpose of the paid-crowdsourcing model is to eliminate these very human connections by using big data and big crowds on an online platform: the whole system stands on the belief that PMs' human judgement can be replaced by algorithms (industry informant, personal communication, September 6, 2016). There is evidence here of a head-on collision of the two conflicting opinions about what technology can do. 
Platform business advocates claim that traditional business models rely too much on "inefficient gatekeepers to manage the flow of value from the producer to the consumer" and in contrast, platform-based businesses can "scale more efficiently by eliminating gatekeepers" (Parker, Van Alstyne, \& Sangeet, 2016, p. 7). Parker et al. use the example of book editors, claiming "editors select a few books and authors from among the thousands offered to them and hope the ones they choose will prove to be popular" (p. 7). Although translation project managers' jobs are different from book editors', there is some commonality between them (both oversee the process of text production), and a sense of undervaluing the gatekeepers of text productin is evident in the above claim by Parker et al. When we assume that the platform business advocates such as Parker et.al belong to the same group of people as the paid-crowdsourscing translation service providers, our PMs' reactions are not surprising: they are sensing that the beliefs and ideologies held by the emerging paid-crowdsourcing businesses are challenging their traditional values ("I must say, I can actually really smell lots of danger here" (G1-2)). It would be reasonable to say that the 'them and us' discourse observed in the discussions is the embodiment of new power struggles between the groups of conflicting values and positions in the present translation industry.

\section{Conclusions and future studies}

The purpose of this article has been to explore the intersection of translation technology and its human reception in order to identify unintended consequences (Morozov, 2013, p. 167) of translation technologies. In the data from focus groups with translation project managers (PMs), two items were identified as posing problems as a result of technological change: 1) uncertainty surrounding the use of machine translation (MT); 2) technology-induced new power struggles. With regard to these items, the following 
points deserve further research.

First, at a pragmatic level, information regarding legal requirements in MT use needs more attention. A lot of uncertainty surrounding the use of MT (Section 3.1) seems to stem from the lack of information about regulations and legal requirements for PMs, particularly regarding the issue of copyright, and this lack of information is preventing communication between PMs and translators. In other words, a fear of detrimental legal consequences is producing a culture of silence. The issue of copyright has been a complex matter in the history of translation (see e.g. Venuti, 1998, p. 47). My data suggests that the emergence of technologies has added more complexity to the issue: translators are now in danger of breaching others' copyrights. Moorkens et al. (2016) provide useful information about copyright ownership of translated texts for translation memory use. This kind of information, but specifically related to MT use, is urgently needed so that practitioners (both PMs and translators) can work without feeling anxious about the risks.

Second, also at a pragmatic level, discussions of fair PEMT pricing are desirable. The concept of pricing in PEMT is muddled and PMs and translators are illinformed. More information about good practice in pricing would make the PMs confident in adopting this model of translation (if they choose to) in future.

Finally, at a more conceptual level, redefinition of the concept of a 'translator', and consequently 'translation' per se, will be necessary. Attempts to reconceptualise 'translation' are not new in translation studies (Halverson, 2010 provides a good review), but the current study has highlighted that the notion of 'translation' is now being challenged by the growth of technologies, and different stakeholders (such as my study participants and large technology companies) are fighting for their own ideologies of translation. The concept of translation is now in flux and PMs' perceptions show a 
high level of uncertainty. For one thing, the definitional boundaries of translators and post-editors are becoming blurry. The PMs' own role as gatekeepers of translation is also being threatened.

The task of re-conceptualising translation is now extremely difficult without the careful consideration of complex, contextual factors. We need to take into consideration, for example, the increasingly diverse needs of the industry. With the rapid growth of web content such as product and service user reviews as well as social media posts, cheaper but quicker translations are increasingly in demand. In other words, people's needs and consequently perceptions of translation now vary greatly depending on the person's role and responsibility in society. As a result, a discussion of "translation" as one single (business) activity is perhaps impossible or even pointless now. 'Polarisation' may not be a sufficient word to describe the state of translation in the future. We may be looking at several stratifications of the industry and, consequently, compound concepts of translation as technology further develops, which will subsequently expand the boundaries of the discipline (Jiménez-Crespo, 2017).

One might argue that the kind of polarisation of translation ideologies observed in section 3.2 is a natural by-product of market development, where PMs have to come to terms with the fact that they have no control over how technologies are developed and adopted. But this kind of social deterministic argument, alongside a technological deterministic argument, undermines the complexities of the issue and fails to explain what challenges stakeholders in translation are facing, which will then prevent the successful integration of technology into the translation process (Olohan, 2011, p. 354). The current study attempted to shed light on such complexities and challenges PMs are experiencing by examining their accounts. But I am also aware that this research has dealt with one homogenous group of people using one type of data and that 
triangulation of different sets of empirical data would be desirable to validate the results. For that purpose, Olohan suggests direct observation of the interaction between technology and humans (2011, p. 353). However, this is not always easy as Risku, Rossmanith, Reichelt, and Zenk (2013, p. 43) report that, in a highly technologised work setting, what researchers can see (or hear) is often only "a lot of clicking!" (emphasis in original). In addition, it would be desirable to solicit PMs' views from different kinds of LSPs (in terms of size, country, services offered etc.) to achieve a more balanced examination of the status quo within the industry. It is hoped that the current study offers a set of data and analysis which contributes to developing a more consistent and comprehensive body of knowledge in the future which will inform scholars, developers and users of translation technologies, and eventually to the STS inspired studies of translation.

References

Adams, D. (1979). The hitchhiker's guide to the galaxy. London: Pan Macmillan.

Cronin, M. (2013). Translation in the digital age. London: Routledge.

Dranch, K. (2016). UK language services market 2016. London: The Association of Translation Companies (ATC).

ELIA, EMT, EUATC, FIT, GALA, \& LIND. (2017). Expectations and concerns of the European Language Industry 2017. Retrieved from https://www.euatc.org/industry-surveys/item/447-2017-language-industry-surveyreport-is-available-for-network-members

Flanagan, M. (2016). Cause for concern? Attitudes towards translation crowdsourcing in professional translators' blogs. JoSTrans, (25), 149-173.

Frey, C. B., \& Osborne, M. A. (2013). The future of employment: How susceptible are jobs to computerisation? Oxford: Oxford Martin Programme on Technology and 
Employment. Retrieved from

http://www.oxfordmartin.ox.ac.uk/publications/view/1314

Garcia, I. (2007). Power shifts in web-based translation memory. Machine Translation, 21(1), 55-68. http://doi.org/10.1007/s10590-008-9033-6

Garcia, I. (2015). Cloud marketplaces: Procurement of translators in the age of social media. JoSTrans, (23), 18-38.

Gengo. (n.d.). Retrieved May 27, 2017, from https://gengo.com

Glaser, B. G., \& Strauss, A. L. (1967). The discovery of grounded theory: Strategies for qualitative research. Chicago: Aldine.

Google. (2014, February 17). From Amharic to Xhosa, introducing Translate in 13 new languages - now over 100 in total! Retrieved August 31, 2017, from https://www.blog.google/products/translate/from-amharic-to-xhosa-introducing/

Halverson, S. (2010). Translation. In L. van Doorslaer \& Y. Gambier (Eds.), Handbook of translation studies. Vol. 1 (pp. 378-384). Amsterdam: John Benjamins.

Jiménez-Crespo, M. A. (2017). Chapter 8 Insights from the sociology of translation. In Crowdsourcing and online collaborative translations: expanding the limits of translation studies. Amsterdam: John Benjamins. Retrieved from http://capitadiscovery.co.uk/port/items/1252156

Kenny, D. (2017). Introduction. In D. Kenny (Ed.), Human issues in translation technology (pp. 1-7). Florence, US: Taylor \& Francis.

Kenny, D., \& Doherty, S. (2014). Statistical machine translation in the translation curriculum: Overcoming obstacles and empowering translators. Interpreter and Translator Trainer, 8(2), 276-294. http://doi.org/10.1080/1750399X.2014.936112

Latour, B. (2003). What if we talked politics a little? Contemporary Political Theory, 2, 143-164. http://doi.org/10.1057/palgrave.cpt.9300092

LeBlanc, M. (2017). “I can’t get no satisfaction!' Should we blame translation technologies or shifting business practices? In D. Kenny (Ed.), Human issues in translation technology (pp. 45-62). Florence, US: Taylor \& Francis.

Moorkens, J. (2017). Under pressure: translation in times of austerity. Perspectives, 25(3), 1-14. http://doi.org/10.1080/0907676X.2017.1285331 
Moorkens, J., Lewis, D., Reijers, W., Vanmassenhove, E., \& Way, A. (2016).

Translation resources and translator disempowerment. In Proceedings of ETHI-

CA2 2016: ETHics In Corpus Collection, Annotation \& Application (pp. 49-53).

Portorož.

Moorkens, J., \& O’Brien, S. (2017). Assessing user interface needs of post-editors of machine translation. In D. Kenny (Ed.), Human issues in translation technology (pp. 110-130). Florence, US: Taylor \& Francis.

Morgan, D. L. (1997). Focus groups as qualitative research, 2nd ed. Thousand Oaks, CA: SAGE.

Morozov, E. (2013). To save everything, click here: Technology, solutionism, and the urge to fix problems that don't exist. London: Allen Lane.

O’Brien, S. (2012). Translation as human-computer interaction. Translation Spaces, 1 , 101-122. http://doi.org/10.1075/ts.1.05obr

O'Hagan, M. (2017). Deconstructing translation crowdsourcing with the case of a Facebook initiative: A translation network of engineered autonomy and trust? In D. Kenny (Ed.), Human issues in translation technology (pp. 25-44). Florence, US: Taylor \& Francis.

Olohan, M. (2011). Translators and translation technology: The dance of agency. Translation Studies, 4(3), 342-357. http://doi.org/10.1080/14781700.2011.589656

Olohan, M., \& Davitti, E. (2015). Dynamics of trusting in translation project management: Leaps of faith and balancing acts. Journal of Contemporary Ethnography, 46(4), 1-26. http://doi.org/10.1177/0891241615603449

Parker, G. G., Van Alstyne, M. W., \& Sangeet, P. C. (2016). Platform revolution: How networked markets are transforming the economy - and how to make them work for you. New York: W.W. Norton \& Company.

Pym, A. (2013). Translation skill-sets in a machine-translation age. Meta, LVIII(3), 487-503.

Richards, L., \& Morse, J. M. (2007). README FIRST for a user's guide to qualitative methods, 2nd edition. London: SAGE.

Risku, H., Rossmanith, N., Reichelt, A., \& Zenk, L. (2013). Translation in the network 
economy. In C. Way (Ed.), Tracks and treks in translation studies: Selected papers from the EST Congress, Leuven 2010 (pp. 29-48). Amsterdam: John Benjamins. http://doi.org/10.1017/CBO9781107415324.004

Rodríguez-Castro, M. (2013). The project manager and virtual translation teams: Critical factors. Translation Spaces, 2, 37-62. http://doi.org/10.1075/ts.2.03rod Sakamoto, A. (2017). Professional translators' theorising patterns in comparison with classroom discourse on translation: The case of Japanese/English translators in the UK. Meta, 62(2), 271-288. http://doi.org/10.7202/1041024ar

Sakamoto, A., Rodríguez de Céspedes, B., Berthaud, S., \& Evans, J. (2017). When Translation Meets Technologies : Language Service Providers (LSPs) in the Digital Age - Focus Group Report [commissioned report by the ITI]. Portsmouth. Retrieved from https://www.iti.org.uk/professionaldevelopment/research/university-of-portsmouth/1087-translation-meetstechnologies

Sismondo, S. (2010). An introduction to science and technology studies, 2nd ed. Chichester: Wiley-Blackwell.

Stepes. (2016, May 10). Stepes Extends Google Translate Model to Live Human Translation. Retrieved May 27, 2016, from http://www.businesswire.com/news/home/20160510005622/en/Stepes-ExtendsGoogle-Translate-Model-Live-Human

The European Commission, The CIOL, \& The ITI. (2017). 2016/17 UK translator survey: Final report. London. Retrieved from http://www.ciol.org.uk/sites/default/files/UKTS2016-Final-Report-Web.pdf

Vashee, K. (2013). Understanding the economics of machine translation. Translation Spaces, 2, 125-149. http://doi.org/10.1075/ts.2.07vas

Venuti, L. (1998). The scandals of translation: Towards an ethics of difference. London: Routledge.

Waverly Labs. (2017). Waverly Labs Sold \$ 5 Million in pre-orders for the Pilot Translating Earpiece A year after their IndieGoGo crowdfunding campaign started, the company announced. New York. Retrieved from http://www.waverlylabs.com/wp-content/uploads/2017/05/PRESS- 
RELEASE_pilottranslatingearpiece_5M.pdf

Wilkinson, S. (2008). Focus Groups. In G. M. Breakwell (Ed.), Doing social psychology research. Chichester, UK: Wiley.

Zaretskaya, A., Corpas Pastor, G., \& Seghiri, M. (2015). Translators' requirements for translation technologies: A user survey. In G. Corpas Pastor, M. Seghiri

Domínguez, R. Gutiérrez Florido, \& M. Urbano Mendaña (Eds.), AIETI7: Nuevos horizontes en los Estudios de Traducción e Interpretación (pp. 247-254). Geneva: Tradulex. Retrieved from http://www.tradulex.com/varia/AIETI7-proc.pdf

Appendix

Questions for the focus groups

(1) Machine translation

- How much do you think translators should use MT in their practice?

(2) CAT Tools

- If you could change one thing about the current CAT tools, what would you change?

- Who do you think should be responsible for managing TM database?

(3) Interpreting-related tools

- How much do digital tools contribute to your interpreters' practice?

- How do they contribute to your interpreting project management?

(4) Training

- Who is training freelance translators? Who should train them? 
- Who is training project managers with digital tools? Who should train them?

(5) Paid-crowdsourcing business model

- If you already use this business model, what benefits (or disadvantages) does this model bring to your practice?

- If you don't, what benefits (or disadvantages) do you think it would bring to your practice if you use it?

(6) Communication tools

- Imagine current communication tools did not exist in this world. How would your practice change? [e.g. translators' forums, social media, blog, online interface portals etc.]

(7) Lastly ...

- Of all the things we discussed, what do you think is the most important for your work?

- Is there anything else we haven't discussed yet that you think is important for us to know about the use of digital tools? 